\title{
The Thermal Wave Method for Investigations of Textile Properties
}

\author{
by M. Michalak ${ }^{1}$ B. Więcek ${ }^{2}$, I. Krucińska ${ }^{1}$ M. Felczak ${ }^{2}$ \\ ${ }^{1}$ Department of Textile Metrology, Technical University of Łódź. Poland \\ ${ }^{2}$ Institute of Electronics, Technical University of Łódź, Poland
}

\section{Abstract}

The results of investigations of new method for textile thermal parameters determinations are presented. Authors of this work in the earlier papers the original solution with using IR mirrors for registration of temperature distribution on opposite surfaces of flat textile product were investigated. This made possible to investigate heat transport in throw direction of product. In the next paper of these authors the thermal wave method was applied and the possibility of heat transport determination along surfaces of product was shown.

The authors trial In this paper connect thermal wave method with IR mirrors method.

\section{Introduction}

In this work, the results of investigations that are continuation of using thermographic method for textile products used for technical and utility purposes [1,2]. In the previous works, it was already discussed that the contactless method for testing of thermal parameters of textile materials is very actual and still under development. A method using 2 mirrors to see both sides simultaneously and measure the heat transfer across the flat material was already presented. In these works the textile material was measured using single impulse of heating and cooling. Temperature distribution was registered on opposite sides of a sample. In [4], thermal wave method was applied to measure temperature distribution on one side only. Both approaches have their limits. In a case of thermal wave method, fast thermal investigations we performed, resulting with longitudinal thermal conductivity, while across parameters are more important for textile domain.

Therefore, in presented work, new both-side investigations using mirrors is combined with thermal wave method.

\section{Study material}

In the present work nonwoven textile materials of different composition were investigated. The nonwovens were manufactured by a needling technique, from polypropylene (PP) and electroconductive fibres, marked as El. The electrocondutive fibres Nitril - Static, manufactured on base of polyacrylonitrile fibres containing copper sulphide co-ordination bounding with functional groups of these fibres, were used. Polypropylene and electroconductive fibres were characterized by different values of electrical resistivity. It was hoped, that electroconductive fibres would be characterized by the different thermoinsulating properties, too. The morphological and electrical properties of fibres were investigated. The tests were provided according to European and Polish standards [5-8]. The length of the PP fibres was $60 \mathrm{~mm}$, the linear density $-2,8 \mathrm{dtex}$, and length and linear density of El fibres were $40 \mathrm{~mm}$ and 3,3 dtex, respectively. The resistance of loose PP fibres was $7,6 \cdot 10^{13} \Omega$ and of electroconductive fibres was $143 \Omega$. 
A nonwoven of multilayer structure was manufactured from the selected fibres. The single layers in these nonwovens were webs from polypropylene and blends of PP and EL fibres. In the first phase a blended web was made from PP and El fibres, of percentage composition 90/10. Further, uniform webs from PP fibres were made. And the same webs were manufactured from blends. The surface mass of each web was $10 \mathrm{~g} / \mathrm{m}^{2}$. The arranged webs were then subjected to the needling process, with the number of needle punches (LP): 40, 80,120 1/cm ${ }^{2}$. The area mass of nonwoven structures was 80,120 and $160 \mathrm{~g} / \mathrm{m}^{2}$.

The ALAMBETA apparatus produced by 'Sensora' company was used for measuring heat-insulating properties. The seven following parameters [9] can be recorded at the same time with the use of this apparatus:

- heat conductivity $\lambda$, in $\mathrm{W} / \mathrm{mK}$;

- heat diffusion $a$, in $\mathrm{m}^{2} \mathrm{~s}^{-1}$;

- thermal absorption b, in $\mathrm{Ws}^{1 / 2} \mathrm{~m}^{-2} \mathrm{~K}$;

- heat resistance $r$, in $\mathrm{Km}^{2} \mathrm{~W}^{-1}$;

- sample thickness $\mathrm{d}$, in $\mathrm{mm}$;

- quotient of maximum and stationary heat flow $p$, and

- maximal density of heat flow in the contact region $\mathrm{g}_{\max }$, in $\mathrm{Wm}^{-2}$.

The thickness and only two parameters of heat-insulating properties were analyzed. The characteristics of multilayer structures are given in Table 1. The investigated characteristics are described below Table 1.

The results in the table 1 show the expected values of morphological parameters of all nonwoven. The thermal conductivity across the nonwovens is almost equal for all investigated sample variants, the thermal absorption is higher for samples with larger layer number and is independent of kind of fibres.

Table 1. Fibre composition and parameters of nonwovens

\begin{tabular}{|l|l|c|c|c|c|c|c|}
\hline No & The code & $\mathrm{Nr}$ & $\mathrm{LP}, \mathrm{cm}^{-2}$ & $\mathrm{M}_{\mathrm{p}}, \mathrm{m}^{2}$ & $\mathrm{~d}, \mathrm{~mm}$ & $\lambda, \mathrm{mW} / \mathrm{m} \cdot \mathrm{K}$ & $\mathrm{b}, \mathrm{W} \cdot \mathrm{s}^{1 / 2} \mathrm{~m}^{-2} \cdot \mathrm{K} ;$ \\
\hline 1 & $\mathrm{PP} / 40-8$ & 8 & 40 & 80 & 5,17 & 39,2 & 27,8 \\
\hline 2 & $\mathrm{PP} / 40-12$ & 12 & 40 & 120 & 6,12 & 39,6 & 31,4 \\
\hline 3 & $\mathrm{PP} / 40-16$ & 16 & 40 & 160 & 7,5 & 39,9 & 35,3 \\
\hline 4 & $\mathrm{PP} / 80-8$ & 8 & 80 & 80 & 4,75 & 39,2 & 35,0 \\
\hline 5 & $\mathrm{PP} / 80-12$ & 12 & 80 & 120 & 6,33 & 40,3 & 39,0 \\
\hline 6 & $\mathrm{PP} / 80-16$ & 16 & 80 & 160 & 7,1 & 40,4 & 40,6 \\
\hline 7 & $\mathrm{PP} / 120-8$ & 8 & 120 & 80 & 4,58 & 39 & 35,6 \\
\hline 8 & $\mathrm{PP} / 120-12$ & 12 & 120 & 120 & 5,57 & 40,3 & 43,8 \\
\hline 9 & $\mathrm{PP} / 120-16$ & 16 & 120 & 160 & 6,43 & 39,9 & 46,7 \\
\hline 10 & $\mathrm{PP}-\mathrm{EL} / 40-8$ & 8 & 40 & 80 & 3,29 & 37,0 & 33,8 \\
\hline 11 & $\mathrm{PP}-\mathrm{EL} / 40-12$ & 12 & 40 & 120 & 5,82 & 39,5 & 37,9 \\
\hline 12 & $\mathrm{PP}-\mathrm{EL} / 40-16$ & 16 & 40 & 160 & 6,09 & 39,4 & 37,0 \\
\hline 13 & $\mathrm{PP}-\mathrm{EL} / 80-8$ & 8 & 80 & 80 & 4,75 & 38,8 & 33,0 \\
\hline 14 & $\mathrm{PP}-\mathrm{EL} / 80-12$ & 12 & 80 & 120 & 6,33 & 39,7 & 35,0 \\
\hline 15 & $\mathrm{PP}-\mathrm{EL} / 80-16$ & 16 & 80 & 160 & 7,1 & 38,3 & 41,6 \\
\hline 16 & $\mathrm{PP}-\mathrm{EL} / 120-8$ & 8 & 120 & 80 & 4,14 & 38,0 & 37,6 \\
\hline 17 & $\mathrm{PP}-\mathrm{EL} / 120-12$ & 12 & 120 & 120 & 5,33 & 39,7 & 32,1 \\
\hline 18 & $\mathrm{PP}-\mathrm{EL} / 120-16$ & 16 & 120 & 160 & 5,84 & 38,2 & 36,9 \\
\hline
\end{tabular}

Designations: $\mathrm{Nr}$ - number of layers, LP - needle punches, $\mathrm{M}_{\mathrm{p}}$ - mass per unit area, $\mathrm{d}$ - sample thickness, $\lambda$ - heat conductivity, $b$ - thermal absorption 


\section{http://dx.doi.org/10.21611/qirt.2006.095}

For the purposes of this work 2 nonwoven variants were chosen: one nonwoven from polypropylene fibres (PP/120-16) and one nonwoven with electroconductive fibre content (PP-EL/120-16). We can see in table 1, that PP/120-16 variant is the nonwoven consisting of 16 webs PP and needle punches equal $120 \mathrm{~cm}^{-2}$, PP-EL /120-16 variant - the same as PP variant but containing El fibres.

For verification of correctness of method the additional investigations on standard uniform flat material with known thermal properties were provided.

\section{Method of investigations}

The investigation method (Fig. 1) was the same, as described in papers [2,3].

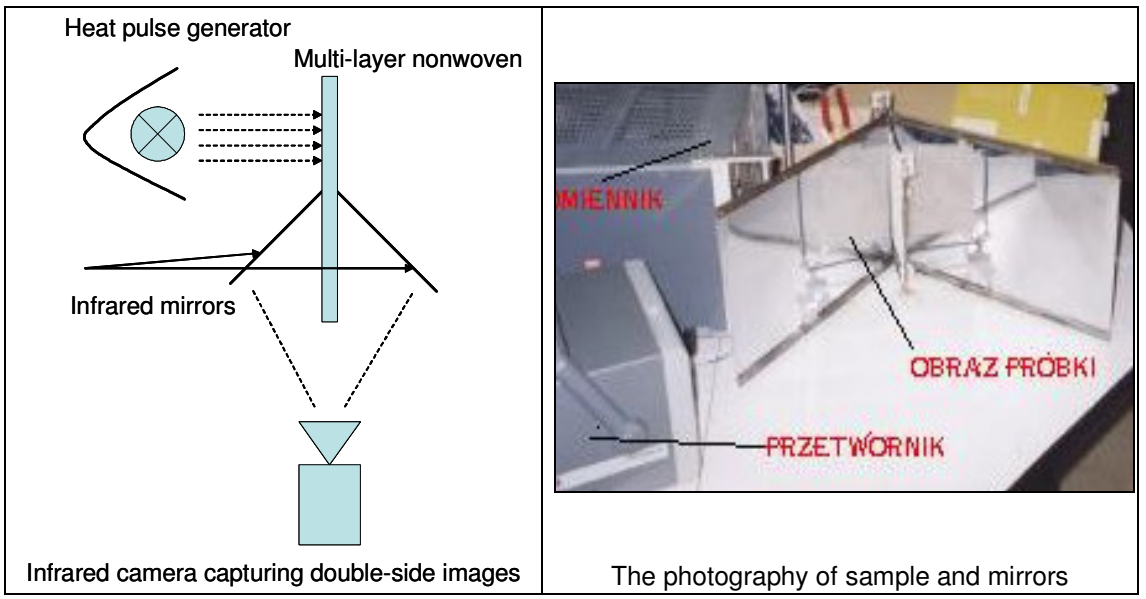

Fig. 1. Thermal measurement setup

The surface of one half of the sample was exposed to the thermal wave generator. The heat flux was transferred along the surface and then to the opposite side of the not heated area of the sample. On the line between the heated and not heated part of the sample, two specially prepared mirrors were placed, at an angle of $90^{\circ}$ to each other (Fig. 1). They were located in such a way, that registration of thermograms from the two opposite surfaces was possible at the same time. The thermovision camera was placed on the line of the longitudinal axis of the sample. Signal from the camera was transmitted to the computer. In this way, it was possible to register temperature distribution on both surfaces of the sample - heated and not heated.

In this stage of investigations the two methods were connected: mirrors method and thermal wave method.

Analysis of the thermograms obtained from the mirror reflection ensures the temperature difference evaluation for points on the opposite surfaces of the sample. The sample under investigation was fixed in specially constructed and prepared frame. The distance of thermovision camera from the sample was $500 \mathrm{~mm}$. Heater, mirrors and samples were insulated from environment.

The exposure process was periodic with frequency $1 \mathrm{~Hz}$. During the measurements, thermal images were registered at the frequency of 2 frame/s and transferred to the computer memory and then analyzed. A sequence of 300 thermograms was obtained. 
The map of temperature distribution reflected in IR mirrors was registered, that means that the temperature distributions on radiated and nonradiated side of sample was analyzed. The amplitude and phase analysis can be carried out.

\section{Results}

The two chosen variants of nonwoven manufactured by identical technological conditions, but with various percent of fibres. Two samples were placed into metallic frame. Each sample was placed in one half of frame. In result the thermographic image for two variants was registered simultaneously. The sample of one variant (PP-EL/120-16) is placed in higher part of frame, the second one (PP/120-16) - in the lower part. The example of thermogram registered in 100 s of heating process is presented in figure 2.

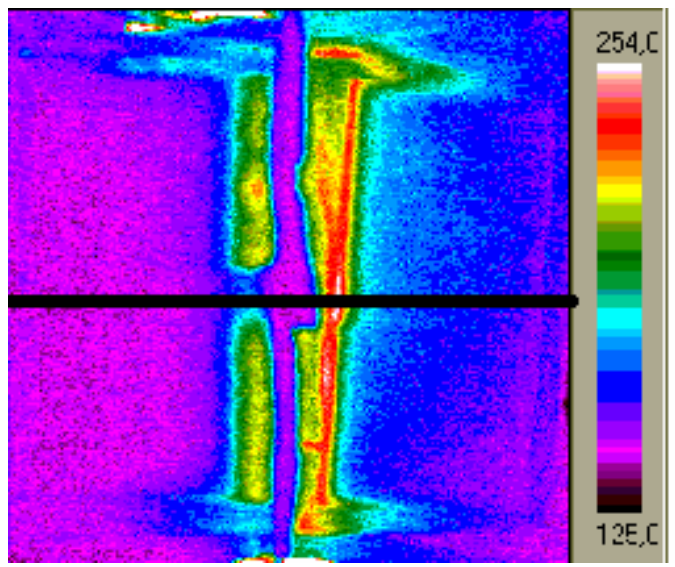

Fig. 2. Thermal images seen in the mirror

The temperature scale is given in contractual units. The value 125 responds $19,5{ }^{\circ} \mathrm{C}$, and value $254-22,8^{\circ} \mathrm{C}$. The right part of image is the reflection from mirror of temperature map on the heated surface of samples. The left part comes from nonheated surface. The horizontal line shows border between samples containing electroconductive fibers (PP-EL/120-16) and samples without electroconductive fibers (PP/120-16). The vertical central area comes from part of frame and isn't analyzed.

The next figure presents temperature in function of heating time for some points marked on thermogram by symbols $A, B, C$ and $D$. $A$ and $B$ points present the temperatures of PP-EL120-16 sample, while $C$ i $D$ points are for PP/120-16. A and C are placed on heated side of surface of sample, $B$ and $D$ points come from exactly opposite surface

The software worked out in this paper allows making the amplitude and phasing analysis of temperature distribution. Fig. 3 presents the amplitude and phase for points marked in 100s of heating. 


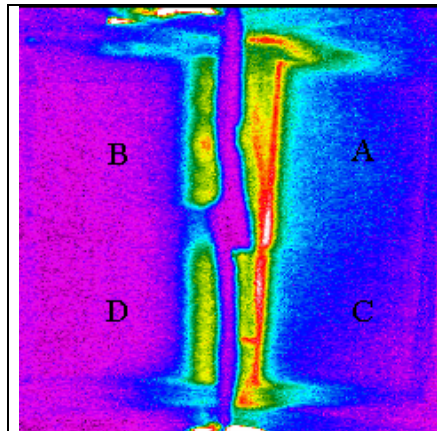

Fig. 3. The analyzed points

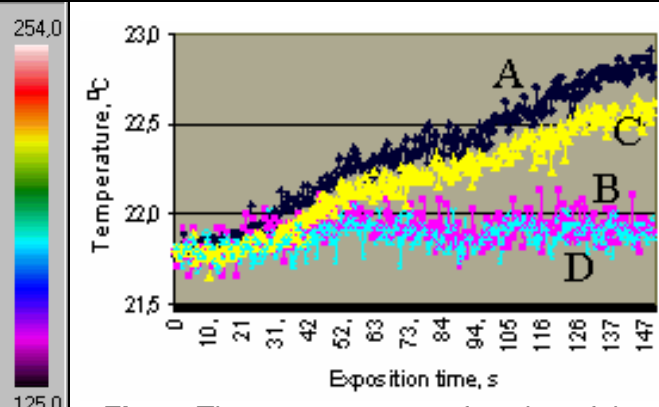

Fig. 4. The temperature as function of time for analyzed points

We can see, that sample containing electroconductive fibers conduct heat in longitudinal direction better than the sample manufactured only from polypropylene fibers. In crosswise direction the better heat conduction is observed for samples without electroconductive fibers. The analysis of thermogram shows that heated area in upper part of image is wider than in sample below. We can also see in figure 4 that in point $A$ the temperature during all time of heating is higher, than in point $C$. In this figure we can see too, that the difference of temperature between opposite points is higher for samples with El fibers, in comparison with homogenous samples, it means, that in crosswise direction the heat energy transport is more intensive as in samples without El fibres.

The applied software enables to present spectral analysis of amplitudes and the analysis of phases for any selected point. In figure $4 \mathrm{a}$ the spectral amplitude analysis for point $A$ form figure 3 is presented, while in figure $4 \mathrm{~b}$ the same for phases.

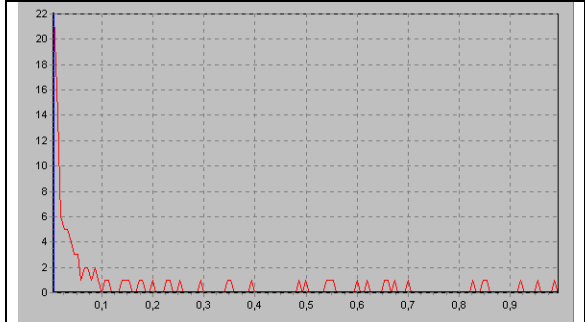

Fig. 4a. The spectrum of amplitudes

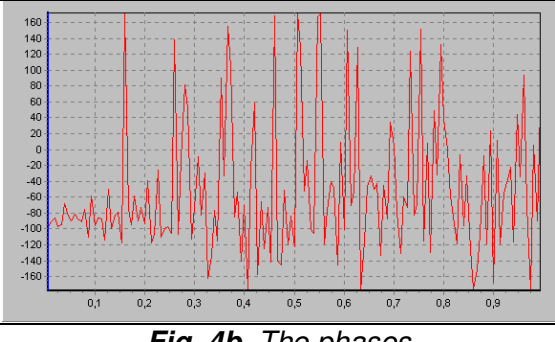

Fig. 4b. The phases

We can obtain the distribution of amplitude and phase for any chosen harmonic component of the spectrum.

In figure $5 \mathrm{a}$, the map of temperature for first harmonic component is presented, and in figure $5 \mathrm{~b}$ - the map of phases. 


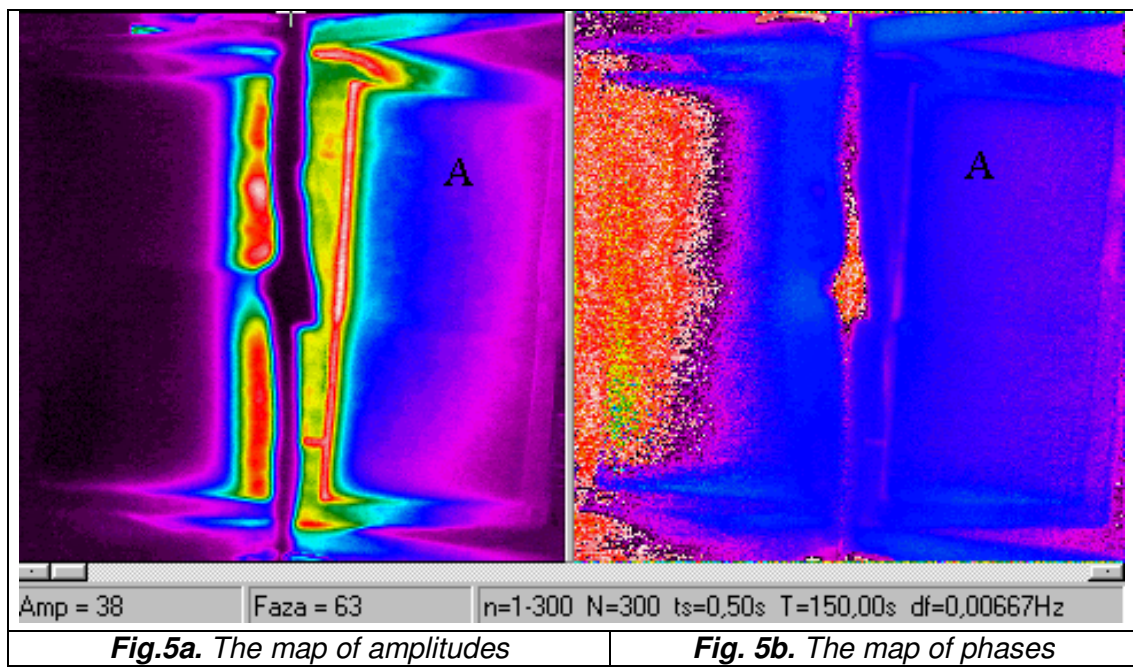

We can obtain the same analysis for each selected harmonic component.

On the picture the point $A$ (the same, as on picture 3 ) is marked. For this point the values of amplitude (in conventional units) and phase are at the bottom of a picture. The parameters of measurement are given too. The results presented on picture 5 relate to the first harmonic component. The same analysis can be obtained for each harmonic signal.

The comparison of phases of the pair of points on opposite sides of tested samples allows calculating the phases in points on opposite sides of a sample.

The amplitude of first harmonic at point $A$ was 27580 in conventional units, and at point $B-3743$. At points $C$ and $D$, the amplitudes had values 21874 and 3307 respectively. The difference of amplitudes of first harmonic for sample PP-EL120-16 was 23837. For sample PP/120-16 this difference was equal 18567 units. We can see, that the variant with electroconductive fibres have higher barrier properties for temperature than a nonwoven manufactured from polypropylene fibres only.

The phase at point $A$ is equal to $-93^{\circ}$, and at point $B$ is $-142^{\circ}$. Respectively, at point $C$ the phase is $-93^{\circ}$ and at point $D$ it is $-113^{\circ}$.

The similar results were obtained for other materials presented in table 1 . The given results show that the proposed method gives possibilities of determining the thermal parameters of material such as heat conductivity and heat resistance, heat diffusion and thermal absorption. The farther investigations are continued.

\section{Conclusions}

The presented results in this paper show that the proposed thermovision method gives many possibilities to test of thermal properties of textile materials by contactless way. These investigations are very important for textile domain and are in progress.

This work was supported by Research Grant Nr 3 T08E 05028 financed by Polish Ministry of Science and Information (contract no. 1061/T08/2005/28). 


\section{http://dx.doi.org/10.21611/qirt.2006.095}

\section{REFERENCES}

1. M. Michalak, M Zimniewska, I. Krucińska, B. Więcek. The Study of Thermal Properties of Linen/PES Fabrics using Thermovision methods. The $3^{\mathrm{d}}$ AUTEX Conference "World Textile Conference", Gdańsk, Polska, 25-27 czerwiec 2003, s. 385393.

2. M. Michalak, B. Więcek, I. Krucińska, M.Lis: "Thermal Barrier Properties of Nonwovens Multilayer Structures Investigated by Infrared Thermography". VII ${ }^{\text {th }}$ Quantitative Infrared Thermography - QIRT 2004, Brussels, Belgium, 5-8 July, 2004.

3. M. Michalak, B. Więcek, I. Krucińska: „Badanie warstwowych układów włókninowych nową metoda termowizyjna", IV Krajowa Konferencja TTP-2004, Ustroń, 6-8 listopada $2004 r$.

4. M. Michalak, M Zimniewska, I. Krucińska, B. Więcek. The physical properties of the surface of apparel made from flax and polyester fibres. $1^{\text {st }}$ International textile, clothing \& design conference - Magic World of Textiles, Dubrovnik, Croatia, October 2002.

5. PN-EN 29073 - 1.Tekstylia. Metody badania włóknin. Wyznaczanie masy powierzchniowej. Textiles. Test methods for nonwovens. Part 1: Determination of mass per unit area.

6. PN-EN 29073 - 3. Tekstylia. Metody badania włóknin. Wyznaczanie wytrzymałości na rozciaganie i wydłużenia. Textiles. Test methods for nonwovens. Part 3: Determination of tensile strength and elongation.

7. PN-EN ISO 9237:1998. Tekstylia. Wyznaczanie przepuszczalności powietrza wyrobów włókienniczych. Textiles. Determination of permeability of nonwovens.

8. PN-91/P-04871. Tekstylia. Wyznaczanie rezystywności elektrycznej. Textiles. Determination of electrical resistivity.

9. Frydrych I., Porada A., Bilska J., Konecki W.; Thermo insulating parameters of fabrics, Przegląd Włókienniczy, 2003, Nr. 10, s. 12-15. 